\title{
A Large Fibroid Uterus Removed with a Bipolar Morcellator
}

\author{
Mohammad Sami Walid, MD, PhD ${ }^{1,2}$; Richard L. Heaton, MD, FACS ${ }^{2}$
}

Keywords: Large Fibroid Uterus; Bipolar Morcellator; Fibroids; Uterus

\begin{abstract}
We report our experience with the use of the PlasmaSord bipolar morcellator on a fibroid uterus weighing over 1500 grams. We suggest some modifications to improve the function of this morcellator to make it more appropriate for advanced laparoscopy procedures.

${ }^{1}$ Medical Center of Central Georgia, Macon, GA.

${ }^{2}$ Heart of Georgia Women's Center, 209 Green Street, Warner Robins, GA
\end{abstract}

\section{Introduction}

The minimally invasive gynecological surgeon frequently resorts to use of morcellators for piecemeal extraction of large uterine masses. The uterus must be devascularized and separated from anchoring structures before morcellation is begun. In this paper we present our first experience with the PKS PlasmaSord morcellator (Olympus, Inc.; Hamburg, Germany) used on a large uterus and the second case with this morcellator in general.

\section{Case Description}

A 41 year-old, gravida 2, para 2, $290 \mathrm{lb}$. female was referred to us for the evaluation of a very large fibroid uterus. The patient had chronic, cyclic pelvic pain and menorrhagia. She had a PUF (Pelvic pain, Urgency, and Frequency questionnaire) score of 10 and 4+ nocturia. The uterus extended above the umbilicus level. Ultrasound showed a large multifibroid uterus with the largest fibroid being $8.3 \mathrm{~cm}$ in diameter. Pap smear was negative and endometrial sampling showed a secretory endometrium. The uterus sounded to 13 $\mathrm{cm}$. The patient was counseled about her status, treatment options, risks and benefits, and her informed consent was obtained to proceed with total laparoscopic hysterectomy (TLH).

A massive multiple fibroid uterus weighing 1525 grams was extirpated (Picture 1). Cystoscopy with hydrodistention revealed scant glomerulations and a reduced bladder capacity of 700 cc. Initially, the operation was completed in 3 hours and 46 minutes. However, additional operative time was required to explore the vagina due to vaginal bleeding and suture the vaginal cuff with \#0 Vicryl, which stopped the bleeding. The scope was reinserted to confirm no additional internal bleeding. The patient never left the operating room and the additional operation time was not related to the morcellation process. Pathological examination of the removed uterus showed leiomyomas without malignant transformation.

In this case, the vascular pedicles were removed in less than half an hour; the remainder of the time was devoted to

Please cite this paper as: Walid MS, Heaton RL. A Large Fibroid Uterus Removed with a Bipolar Morcellator. Proc Obstet Gynecol. 2011 Apr;1(3):Article 11[4p.]. Available from: http://ir.uiowa.edu/pog/. Free full text article.

Corresponding author: Mohammad Sami Walid, Heart of Georgia Women's Center, Warner Robins, GA 31093-2727, mswalid@yahoo.com 
the morcellation process. We used the PKS PlasmaSord morcellator over several hours (Picture 2). The morcellator's shaft inner diameter is 12 $\mathrm{mm}$ and the outer diameter is $15 \mathrm{~mm}$. It functions by the principle of bipolar cutting instead of mechanical blades.

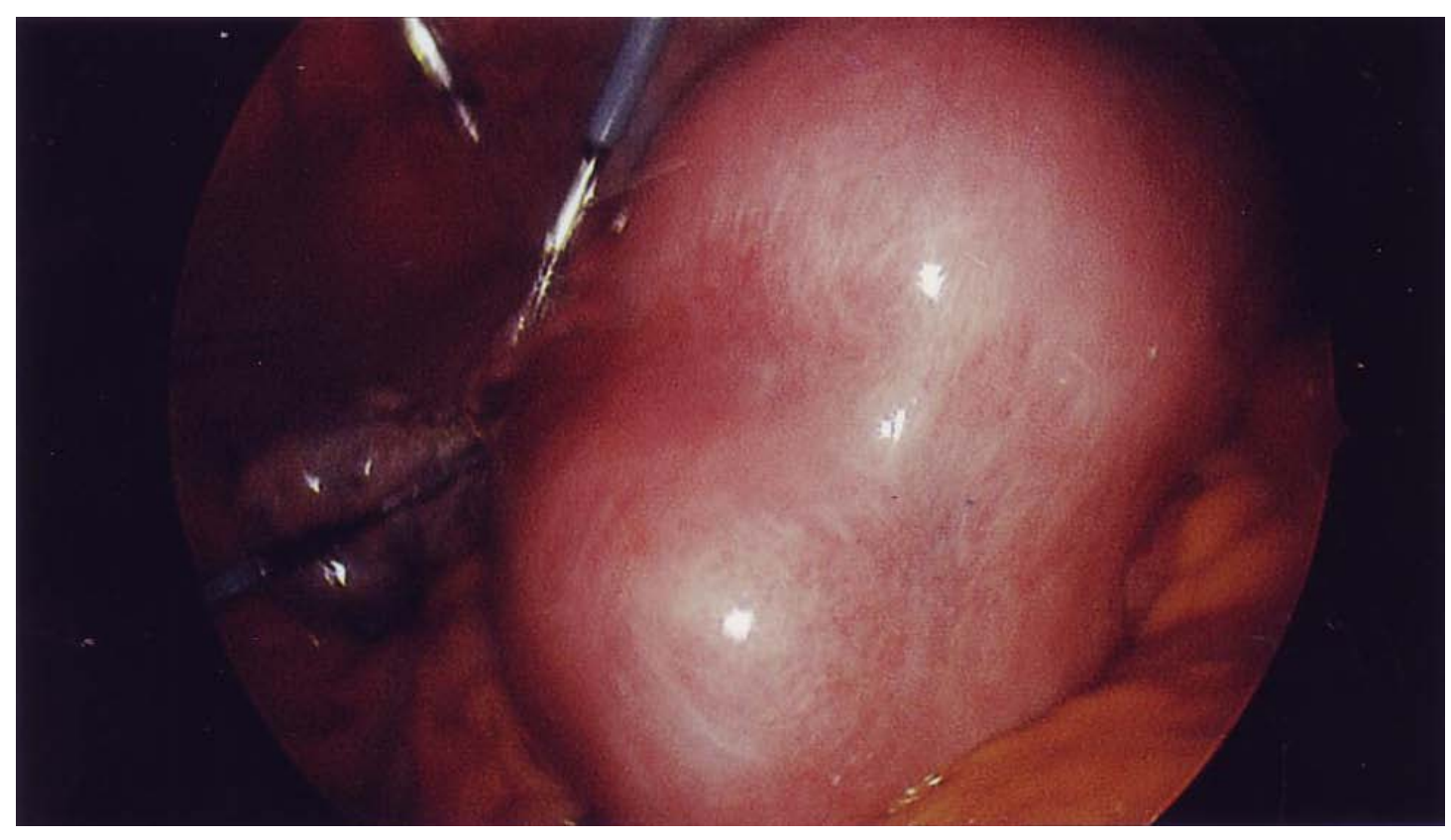

Picture 1: The large multifibroid uterus.

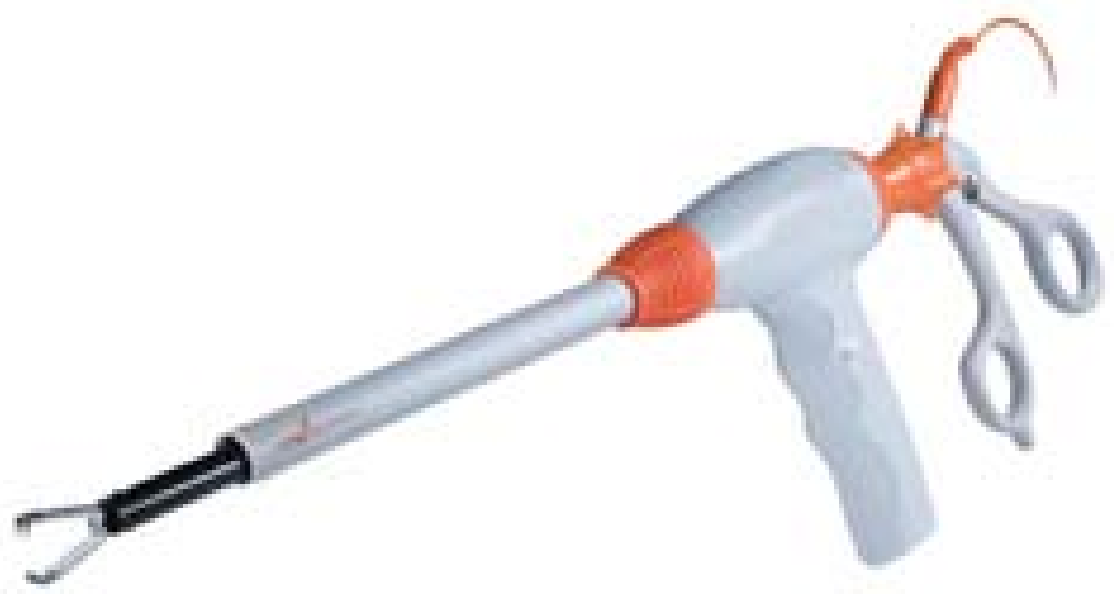

Picture 2: The PKS PlasmaSord Bipolar Morcellator.

http://www.olympus.eu/endoscopy/427 PK Technology PlasmaSORD.htm 


\section{Commentary}

Previously, we reported a case study of nine patients that were successfully treated for large fibroid uteri laparoscopically with postoperative specimens weighing over 1000 grams 1,2 . One patient had a laparoscopicallyassisted vaginal hysterectomy, and eight patients had a total laparoscopic hysterectomy. The last six cases were total laparoscopic hysterectomy cases. The case presented herein represents our tenth patient with a uterus over 1000 grams removed laparoscopically. This case was an aberration; it is the only case that had an acute cuff bleeding in the author's over $700 \mathrm{TLH}$ series, and this report is not about that but a critique of the PlasmaSord morcellator.

We believe that this morcellator is a general purpose morcellator that is engineered for surgeons with limited laparoscopic skills to allow them to perform supracervical hysterectomy, a procedure that is considered by the senior author and many older generation gynecologists to be a suboptimal procedure ${ }^{3}$. The PlasmaSord morcellator is still not qualified to be a tool for advanced laparoscopic surgeons who remove large fibroids and large uteri. The cannula with a $12 \mathrm{~mm}$ diameter is not sufficient to remove large fibroids of over 1000 grams $^{1,2}$. A large cannula, preferably $20 \mathrm{~mm}$ in diameter, would allow removal of larger chunks of fibroid tissue and shorten operative time. The foot activation system is not convenient for the physician or safe for the patient because the surgeon is constantly trying to locate the pedal under his foot, thereby taking his attention away from the operative field. Hand activation would be preferable. The addition of a V-shaped guide on the cannula that allows the morcellator to skim over the surface of the uterine mass and prevent coring into it would also improve the device. The lack of an adequate smoke evacuation system to prevent obscuring the surgical scene with dense smoke during bipolar morcellation is also a major problem with this device. A high volume evacuator at the site of energy use could be incorporated in the upper surface of a $V$ guide to keep smoke out of the operative field and prevent leaking into the operating room air.

On the other hand, most electromechanical morcellators are also of small diameter. This makes morcellation of large uterine masses a tedious task and leads to motor overheating, which requires stopping the morcellation process several times during the operation ${ }^{2}$. The use of $a \geq 20$ $\mathrm{mm}$ diameter morcellator (Wisap Powerdrive 7688PD1, Sauerlach, Germany) may prevent such difficulties and shorten operative time. These devices are unfortunately not readily available in the USA.

Generally, we would prefer the concept of the PKS PlasmaSord bipolar morcellator over that of mechanical morcellators if the above suggested improvements are incorporated into the design. 


\section{References}

1. Walid MS, Heaton RL. Total laparoscopic hysterectomy for uteri over one kilogram. JSLS. 2010 Apr-Jun;14(2):178-82.

2. Walid MS, Heaton RL. Laparoscopic extirpation of a 3-kg uterus. Arch Gynecol Obstet. 2009 Apr;279(4):607-8. Epub 2008 Nov 15.

3. Kives S, Lefebvre G, Wolfman W, Leyland $\mathrm{N}$, Allaire C, Awadalla A, Best C, Leroux N, Potestio F, Rittenberg D, Soucy R, Singh S. Supracervical hysterectomy. J Obstet Gynaecol Can. 2010 Jan;32(1):62-8.
No Conflict of Interest: The authors are not affiliated with Olympus Corporation and did not receive financial compensation for preparing this manuscript. 